\title{
Methotrexate in the Treatment of Recalcitrant Nodular Vasculitis
}

\author{
Sudip Parajuli,' Kamal Raj Dhital ' \\ 'Department of Dermatology and Venerology, Tribhuvan University Teaching Hospital, Kathmandu, Nepal.
}

\section{ABSTRACT}

We report a case of recalcitrant nodular vasculitis in a 23 years old male who was treated successfully with methotrexate. He presented to our Dermatology out Patient Department, Tribhuvan university teaching hospital with complaints of recurrent painful discharging ulcer over bilateral calf and lower legs of three years duration. The diagnosis of nodular vasculitis was made on the basis of the clinical presentation and the histopathological findings. The patient was treated with antituberculosis treatment with initial good response; however the lesions persisted later on, despite completing the course of ATT. The patient did not respond to treatment with systemic corticosteroids also. On starting methotrexate, the lesion started healing within a period of two weeks and there was significant improvement in subsequent one month. This case report highlights the efficacy of methotrexate in the treatment of recalcitrant nodular vasculitis.

Keywords: ATT; methotrexate; nodular vasculitis.

\section{INTRODUCTION}

Erythema induratum is a chronic, relapsing, most common form of lobular panniculitis with septal vasculitis. It occurs primarily as erythematous tender nodules or plaques on the calf and lower legs of middle aged women that may progress to ulceration. ${ }^{1}$ Though historically classified as erythema induratum of Bazin as tubercular origin and erythema induratum of whitfield /nodular vasculitis as nontubercular in origin, currently most authors use both the terms as synonymous to describe this form of pannuculitis. ${ }^{2}$ In those cases associated with tuberculosis (TB) , a full course antitubercular treatment(ATT) regimen is given ${ }^{2}$ and even in those cases not associated with TB most authors favor $\mathrm{ATT}^{3}$ Other therapeutic options are potassium iodide, oral corticosteroids, mycophenolate mofetil and simple measures such as compression, bed rest and NSAIDs. ${ }^{4}$ There are only few literatures citing the efficacy of methotrexate in nodular vasculitis. In our case methotrexate proved to be very effective in treatment of ATT and steroid resistant long standing case of erythema induratum.

\section{CASE HISTORY}

A 23 year old male presented to TUTH Dermatology OPD with the complaints of recurrent discharging ulcer over the bilateral calf and lower legs of three years duration (Figure 1). The lesion started as deep seated nodules which ruptured over the period of few weeks to form chronic discharging ulcers. There was past history of taking oral steroids repeatedly and completion of ATT for the management of same. However, the lesions had not been responsive to all these treatment modalities.

At the time of presentation to our OPD, there were multiple, well demarcated erythematous, punched out

Correspondence: Dr. Sudip Parajuli, Assistant Professor, Department of Dermatology and Venerology, Tribhuvan University Teaching Hospital, Kathmandu, Nepal. E-mail: sudipparajuli@gmail.com, Phone: +977- 9841360276 . 
ulcer with irregular margin measuring $3 \times 3 \mathrm{~cm}$ to $5 \times 8$ $\mathrm{cm}$ with the necrotic slough over the base interspersed with multiple atrophic scar on the bilateral calf and lower leg. All the routine and specific blood investigations were within the normal limit. An incisional biopsy was done from the lesion. Biopsy showed features suggestive of Nodular vasculitis. Based on history, clinical examination and histopathology report we started patient on tapering dose of oral steroids for 3 months followed by CAT I ATT for eight months which caused temporary improvement of lesion. However the lesion recurred after nearly 2 months of completion of ATT. We then again repeated biopsy of the lesion which showed same features as in previous biopsy. The patient was started on low dose weekly methotrexate (15mg weekly). The lesions started to improve after about 2 weeks of starting treatment (Figure 2). There was no recurrence up to 5 months of follow up.


\section{DISCUSSION}

Erythema induratum of bazin was described by Bazin in the year 1861 as indurated plaques on legs of middle aged woman which later was found to be associated with tuberculosis and later similar entity not associated with tuberculosis was nomenclatured as Erythema induratum of Whitfield's. Later American physician termed nodular vasculitis for whitfield's erythema induratum. At present, both the terms nodular vasculitis and erythema induratum of Bazin are used interchangeably. ${ }^{2}$

Though classically associated with tuberculous infection, erythema induratum has also been associated with both infectious non tubercular and noninfectious disorders. ${ }^{4}$ Infectious non tubercular causes include nocardia, pseudomonas and fusarium ${ }^{4}$ and are also associated with chronic hepatitis $\mathrm{C}^{5}$ and hepatitis B infections. ${ }^{5}$ Noninfectious causes include superficial thrombophlebitis, hypothyroidism, chronic lymphoblastic leukemia, rheumatoid arthritis and crohn's disease. ${ }^{5}$ Histopathology primarily shows lobular panniculitis with varying degree of septal involvement with primarily neutrophilic vasculitis of nearby vessels. As the lesions fully develop there are epitheloid histiocytes, multinucleated giant cells and lymphocytes contributing to granulomatous appearance of inflammatory infiltrates. ${ }^{5}$

Treatment of nodular vasculitis involves general measures such as compression, bed rest and NSAIDs. ${ }^{4}$ In patients in whom Tuberculosis has been documented antitubercular treatment should be given ${ }^{2}$ and even in those cases not associated with TB. Most authors favor ATT treatment. ${ }^{3}$ Drugs which are effective in cutaneous small vessel vasculitis (CSVV) may also be tried for the treatment of Nodular Vasculits ${ }^{1}$. Other treatment modality includes systemic steroids, potassium iodide, ${ }^{1}$ dapsone $^{6}$ and mycophenolate mofetil. ${ }^{7}$ Methotrexate has been shown to be effective in a study done by prajapati et al. ${ }^{8}$ Methotrexate is a folate antagonist that competitively inhibits Dihdrofolate Reductase preventing the reduction of folate cofactors resulting in inhibition of thymidylate synthesis and thus preventing pyrimidine synthesis. ${ }^{9}$ In addition methotrexate in low dose inhibits the enzyme aminomidazole-4-carboxamide ribonucletide (AICAR) transformylase enzyme that inhibits de novo purine synthesis and promotes the accumulation of AICAR. AICAR inactivates adenosine monophosphate dehydrogenase and so leads to intracellular as well as extracellular accumulation of adenosine and is responsible for anti-inflammatory effect of low dose of methotrexate. ${ }^{10}$ In our case significant improvement of lesion was seen with the methotraxate which may be due to anti inflammatory action of low dose of methotrexate. As the patient had relapsing lesions while on steroids and ATT, methotrexate was chosen based on literatures of its efficacy in cutaneus small vessel vasculitis. The patient responded very well to the treatment and there was no recurrence even 
after 5 months of follow up.

\section{CONCLUSION}

Nodular vasculitis can sometimes be refractory to treatment with ATT and Steroids. In such cases low dose methotrexate may be used to initiate remission. Our case highlights the fact that low dose weekly methotrexate could be effective in treating Nodular
Vasculits, and might be used as a useful alternative treatment

\section{ACKNOWLEDGEMENT}

We would like to acknowledge Prof. Dr DB Pokhrel and Prof. Dr Dwarika P Shrestha for their continuous encouragement and supervision for writing this manuscript.

\section{REFERENCES}

1. Cox NH et al. Rook's Textbook of Dermatology. 8th edn. UK:Wiley- Blackwell 2010; chapter 50, Vasculitis, Neutrophilic Dermatoses and Related Disorders; pages 50.1- 50.95 .

2. Requena L, Sánchez YE.Panniculitis. Part II. Mostly lobular panniculitis. J Am Acad Dermatol. 2001 Sep; 45(3):325-6.

3. Mascaró JM Jr, Baselga E.Erythema induratum of bazin. DermatolClin. 2008 Oct;26(4):439-45.

4. Gilchrist H, Patterson JW. Erythema nodosum and erythema induratum (nodular vasculitis): diagnosis and management. DermatolTher. 2010 aJul-Aug;23(4):320-7.

5. Segura S, Pujol RM, Trindade F, Requena L.Vasculitis in ery thema induratum of Bazin: a histopathologic study of $101 \mathrm{bi}$ opsy specimens from 86 patients. J Am AcadDermatol. 2008 Nov;59(5):839-5

6. Nath et al,NodularVasculitis Responding to Dapsone. Egyptian Dermatology Online Journal 2010 Dec; 6(2):11.
7. Taverna JA, Radfar A, Pentland A, Poggioli G, Demierre MF. Case reports: nodular vasculitis responsive to mycophenolate mofetil.J Drugs Dermatol. 2006 Nov-Dec;5(10):992-3.

8. Prajapati V, Steed M, Grewal P, Mahmood MN, Verma $G$, Brassard A.Erythema induratum: case series illustrating the utility of the interferon- $\gamma$ release assay in determining the association with tuberculosis. J Cutan Med Surg. 2013 Oct;17 Suppl 1:S6-S11.

9. Shen S, O'Brien T, Yap LM, Prince HM, McCormack CJ. The use of methotrexatein dermatology: a review.Australas J Dermatol. 2012 Feb;53(1):1-18

10. Malaviya AN, Sharma A, Agarwal D, Kapoor S, Garg S, Sawhney S.Low-dose and high-dose methotrexate are tw o different drugs in practical terms.Int J Rheum Dis. 2010 Oct;13(4):288-93. 